Preprint to appear in Studies in History and Philosophy of Science, doi: 10.1016/j.shpsa.2020.09.010. Please quote published version.

\title{
The Death of the Cortical Column? Patchwork structure and conceptual retirement in neuroscientific practice
}

\author{
Philipp Haueis \\ Bielefeld University \\ Department of Philosophy \\ Postfach 100131 \\ D- 33501 Bielefeld \\ Email: philipp.haueis@uni-bielefeld.de \\ Phone: +49521064585
}

\begin{abstract}
In 1981, David Hubel and Torsten Wiesel received the Nobel Prize for their research on cortical columns - vertical bands of neurons with similar functional properties. This success led to the view that "cortical column" refers to the basic building block of the mammalian neocortex. Since the 1990s, however, critics questioned this building block picture of "cortical column" and debated whether this concept is useless and should be replaced with successor concepts. This paper inquires which experimental results after 1981 challenged the building block picture and whether these challenges warrant the elimination "cortical column" from neuroscientific discourse. I argue that the proliferation of experimental techniques led to a patchwork of locally adapted uses of the column concept. Each use refers to a different kind of cortical structure, rather than a neocortical building block. Once we acknowledge this diversekinds picture of "cortical column", the elimination of column concept becomes unnecessary. Rather, I suggest that "cortical column" has reached conceptual retirement: although it cannot be used to identify a neocortical building block, column research is still useful as a guide and cautionary tale for ongoing research. At the same time, neuroscientists should search for alternative concepts when studying the functional architecture of the neocortex. KEYWORDS: Cortical column, conceptual development, history of neuroscience, patchwork, eliminativism, conceptual retirement
\end{abstract}

Acknowledgments: I thank Alkistis Elliot-Graves, Stefano Canali, Javier Suárez Diaz, Fabian Hundertmark, Marie Kaiser, Aaron Novick, Maria Ferreira Ruiz, and Rose Trappes, for helpful comments on previous drafts of this paper. Two anonymous reviewers provided insightful feedback which greatly improved the structure and argument of the paper. 
Preprint to appear in Studies in History and Philosophy of Science, doi: 10.1016/j.shpsa.2020.09.010. Please quote published version.

\section{Introduction}

The concept "cortical column" refers to vertical bands of neurons in the neocortex which show similar firing patterns in response to sensory stimuli. The column concept was introduced by Mountcastle (1957) to describe the distribution of sensory afferents in primary somatosensory cortex. Hubel and Wiesel (1977) subsequently extended it to describe the primary visual cortex (V1) as being composed of hypercolumns. These $2 \times 2 \mathrm{~mm}$ blocks of tissue consist of orientation columns responding to visual stimuli at different angles and orthogonally positioned ocular dominance columns responding to input from either eye. Hypercolumns can analyze the "building blocks of perception" (ibid., p. 17) since they contain the machinery to process basic visual features. In 1981, Hubel and Wiesel received the Nobel Prize for physiology and medicine (together with Roger Sperry) for their research on the columnar organization of V1.

Column research between 1955 and 1981 led to what I call—building on Haueis (2016) — the classical columnar outlook. Its commitments can be summarized as follows:

(C1) Anatomical modularity: cortical columns have discrete anatomical boundaries. Vertical neuron bands - called minicolumns - are separated by cell-sparse zones of neuropil (Rockel, Hiorns \& Powell 1980) and are heavily vertically interconnected and sparsely horizontally connected (Mountcastle 1978, p. 36). Similarly, larger columnar structures like ocular dominance columns form nonoverlapping zones of cells and connections (Hubel \& Wiesel 1977, p. 21).

(C2) Functional modularity: neurons within a type of column show modality-specific, uniform functional responses to the same type of sensory stimulus. Neurons in somatosensory columns respond to the same tactile modality (Mountcastle, 1957), neurons in orientation columns respond to the same angle of orientation (Hubel and Wiesel, 1977). Such responses shift abruptly between columns.

(C3) Intrinsic function: Across mammalian evolution, column size remains constant while column number changes (Szentágothai, 1978, p. 223). Thus, columnar modules execute the same, modality-independent intrinsic computational function which underlies different sensory and higher cognitive functions across neocortical areas and species (Mountcastle, 1978, p. 9, Eccles, 1981). ${ }^{1}$

Besides (C1)-(C3), the classical columnar outlook also provides strategies to infer columnar functional architecture from electrophysiological and anatomical data, and to deal with counterevidence (Haueis, 2016, p. 14). The success of the classical columnar outlook supported the building block picture, i.e. the view that "cortical column" refers to an anatomically discrete

\footnotetext{
${ }^{1}$ (C3) distinguishes columnar modules from mental modules (Fodor 1983). While both are informationally encapsulated, have a characteristic ontogeny and fast speed/shallow outputs, the computational function of columns is modality-independent, while computation in mental modules is modality-specific (cf. Ebdon 1993, p. 386).
} 
Preprint to appear in Studies in History and Philosophy of Science, doi: 10.1016/j.shpsa.2020.09.010. Please quote published version.

functional module that is the basic building block of the mammalian neocortex (Mountcastle 1978; Szentagothai, 1978, Rockel Hiorns \& Powell, 1980; Eccles, 1981).

Beginning in the 1990s, however, critics began to debate the significance of the classical columnar outlook and the adequacy of the building block picture (Swindale, 1990; Purves, Riddle \& LaMantia; 1992, Catania, 2002). Against (C1) they argued that vertical neuron bands are heavily interconnected across column boundaries and that larger columnar structures lack discrete boundaries. Against (C2) they argued that functional responses are sometimes diverse within and shift gradually between columns. Against (C3) they pointed out that the functionality of columnar structures varies across mammalian species. These criticisms reached their pinnacle in a review of 50 years of column research by Horton and Adams (2005). This review sparked a debate about the "death" of the cortical column (DaCosta \& Martin, 2010) and the usefulness of the column concept for understanding functional cortical architecture (Rakic, 2008; Molnár, 2013). From the perspective of history and philosophy of science, this debate poses a descriptive and a normative question. The descriptive question is: which experimental results between 1981 and 2005 challenged the classical columnar outlook? The normative question is: given these challenges, is the column concept still useful today or should we eliminate it from neuroscientific discourse?

In this paper, I answer the descriptive question by analyzing three strands of column research between 1981 and 2005, in which the use of novel experimental techniques produced results which challenged commitments $(\mathrm{C} 1)-(\mathrm{C} 3)$ of the classical columnar outlook. Section 2.1 describes research on cytochrome oxidase blobs and visual pathways, which challenged the view that modules at the hypercolumn scale have discrete anatomical boundaries (C1). Section 2.2 describes research on higher visual and nonvisual areas which challenges $(\mathrm{C} 2)$, because it revealed that columns can show functionally diverse responses and that many areas have a complex, non-columnar functional architecture. Section 2.3 shows that the classical columnar outlook initially remained fruitful to study columnar microanatomy, since it provided strategies to deal with evidence against the anatomical modularity of orientation and ocular dominance columns. Yet the closer study of horizontal connections in the mid 2000s revealed that minicolumns have no discrete boundaries, which called into question that that minicolumns are autonomous vertical units which compute an intrinsic function (C3). By answering the descriptive question, I complete the historiographical project of following the conceptual development of the column concept into the present (Haueis, 2016). 
Preprint to appear in Studies in History and Philosophy of Science, doi: 10.1016/j.shpsa.2020.09.010. Please quote published version.

My answer to the normative question has two parts. The first part proposes a patchwork model to evaluate the utility of the column concept (section 3). According to this model, research between 1981 and 2005 resulted in multiple local uses or patches of the column concept. These patches are linked together into a patchwork structure because neuroscientists reuse experimental techniques to describe novel columnar structures and combine patches to draw inferences about the functional architecture of the neocortex (section 3.1). I use the patchwork model to argue that we should replace the building block with the diverse-kinds picture. There is no general definition of "cortical column"; only multiple, equally legitimate uses of this concept which pick out different kinds of columnar structure. None of these kinds is the basic neocortical building block, and none computes a common intrinsic function. The column concept aids researchers in classifying this diversity of columnar structures and understand their relations to each other. My analysis thus supports the view that concepts in the physical and life sciences consist of a patchwork of related meanings and uses operating under the guise of a univocal concept (Wilson, 2006, 2017; Bursten, 2016; Novick, 2018; Haueis, 2018; Burnston \& Haueis, 2020).

Based on the patchwork model, I argue that the concept should not be eliminated, but instead taken to be in conceptual retirement (section 4). Philosophers of science like Taylor and Vickers (2017) hold that concepts with multiple meanings should be eliminated when they result in miscommunication and pointless debate. I argue that the patchwork model of "cortical column" makes eliminativism unnecessary (section 4.1$).^{2}$ Once we switch from the building block to the diverse-kinds picture, the threat of miscommunication disappears and the debate about the columnar functionality is resolved. Yet, the utility of "cortical column" is seriously limited, which is why I suggest its conceptual retirement of the column concept (section 4.2). A concept reaches retirement if it permanently fails to serve the central epistemic goal for which it was created. ${ }^{3}$ For "cortical column", that goal was to identify a neocortical building block. Yet a retired concept is not completely useless, since it can contribute to goals that are independent from this central goal. While retirement implies that researchers are no longer normatively bound to describe results from these studies in terms of columns, they can still use column research as both a guide and a cautionary tale when studying the organization of the neocortex.

\footnotetext{
${ }^{2}$ I exclusively defend the patchwork model against eliminativism here. A comparison of the patchwork model with other theories of concepts and conceptual change is beyond the scope of this paper.

${ }^{3}$ I follow Brigandt (2010) and include the epistemic goal into the content of a concept. Whereas Brigandt focuses on explanatory goals and aims to select one epistemic goal to justify conceptual change as rational, I emphasize that the column concept can serve different kinds of goals (e.g., identifying a building block, studying development), which are partially independent of another.
} 
Preprint to appear in Studies in History and Philosophy of Science, doi: 10.1016/j.shpsa.2020.09.010. Please quote published version.

\section{Three challenges to the classical columnar outlook (1981-2005)}

\subsection{Challenge 1: Functional modules without discrete anatomical boundaries}

The first challenge to the classical columnar outlook is that after 1981, neuroscientists used the term "hypercolumn" to refer to functional modules that have no discrete anatomical boundaries. Until the mid 2000s, research on hypercolumns presented the primary challenge to anatomical modularity because researchers successfully used the classical columnar outlook to reinterpret evidence against discrete anatomical boundaries of columns and minicolumns (section 2.3). Hypercolumns challenged (C1) because they were only defined by the sequence regularity of their functional responses. In V1, the responses to orientation and inputs from the left/right visual field form regular sequences which re-occur every $2 \mathrm{~mm}$. Thus, the ice-cube model describes V1 as composed of $2 \times 2 \mathrm{~mm}$ functional modules. But the boundaries between these modules are "arbitrary" (Hubel \& Wiesel 1977, p. 41); they do not correspond to anatomical locations. This situation apparently changed with the discovery of cytochrome oxidase blobs, which gave the functional modules an anatomical reality.

After 1981, Hubel adopted the technique of staining with cytochrome oxidase (CO) to study visual pathways, while Wiesel used other techniques to study columnar microanatomy (section 2.3). Using the $\mathrm{CO}$ technique, Hubel (1986) showed that V1 contained a regular pattern of $200 \mu \mathrm{m}$ wide "blobs" in layers $2 / 3$ and 5/6, shown in Fig. 1a. Since the CO blobs are each $400 \mu \mathrm{m}$ apart and are located at the center of ocular dominance columns (ibid., p. 94), column researchers located four of them in each hypercolumn, as shown in the updated ice-cube model in Fig. 1b. This spatial relation of CO blobs and ocular dominance columns seemed to support (C1). The anatomical boundaries of a hypercolumns are the outer boundary of the left and the right ocular dominance column, respectively. 
a

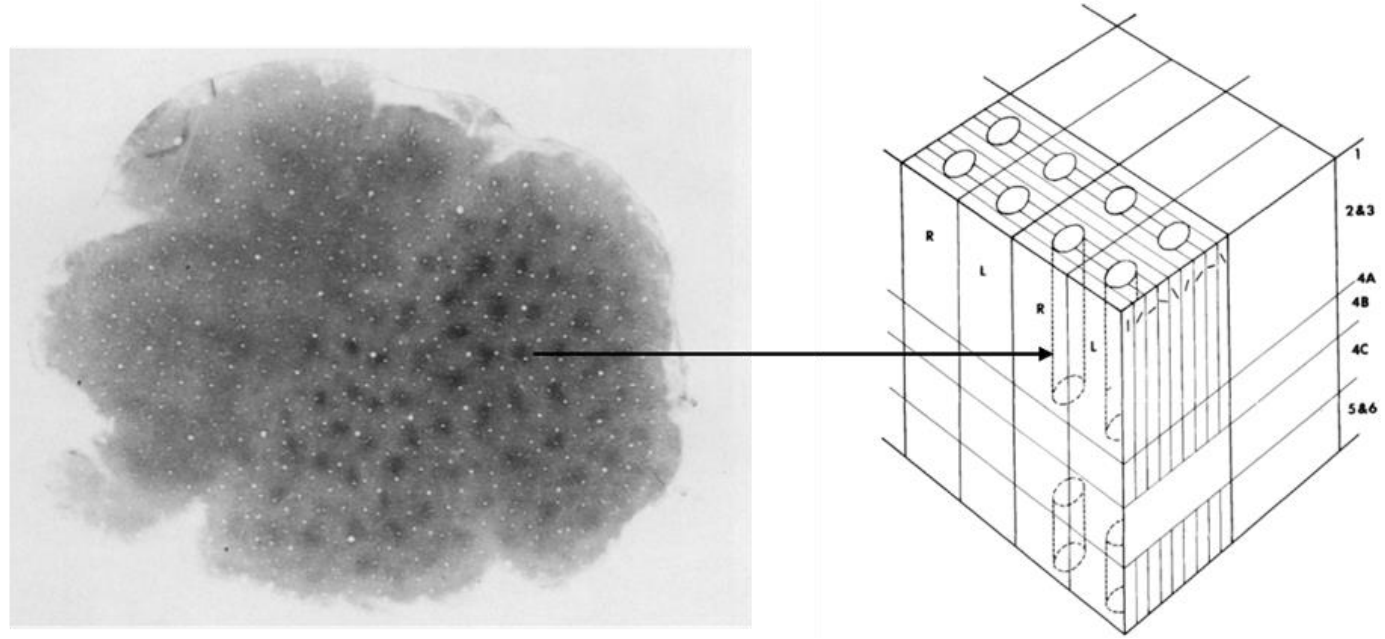

Fig. 1 a. CO staining running through layer 3 of area 17 (V1, lower right) and area 18 (V2, upper left) in squirrel monkey (Hubel 1986, Fig. 5a). b. Ice-cube model of V1 with CO blobs (ibid., Fig. 8).

Despite this initial support of the classical columnar outlook, there are three reasons why research on $\mathrm{CO}$ blobs ultimately failed to establish the anatomical modularity of hypercolumns. First, the relation between ocular dominance columns and CO blobs in V1 is unclear. The centers of CO blobs cannot be identified unambiguously because they have "vague boundaries, are not circular and often blend into each other" (Horton \& Adams 2005, p. 849). And even if CO blob centers can be identified, their relation to ocular dominance columns is difficult to determine experimentally. Physiological recordings of ocular dominance and post-mortem CO staining are difficult to align, an issue that already plagued Mouncastle's attempt to identify anatomical boundaries of columnar structures (Haueis 2016). Finally, the relation of CO blobs and ocular dominance columns varies between species (Horton \& Adams 2005, p. 848). This questions whether discrete anatomical boundaries of hypercolumns, if they exist, are a feature of the basic building block of mammalian neocortex (section 3.2).

Second, the results from using the CO technique supported the modular functional hier$\operatorname{archy}(\mathrm{MFH})$ view without committing researchers to (C1). The MFH view explains perception as the feedforward processing of increasingly abstract (i.e. stimulus-invariant) representations (Burnston, 2016). The MFH view emerged from Hubel and Wiesel's hierarchical wiring scheme of orientation-selective cells in V1, and thus was initially embedded in the classical columnar outlook (Haueis 2016, Burnston \& Haueis, 2020). Through research on CO blobs, however, the MFH view became dissociated from that outlook and consequently, neuroscientists using the $\mathrm{CO}$ technique investigated functional modules without positing discrete anatomical boundaries. 
Preprint to appear in Studies in History and Philosophy of Science, doi: 10.1016/j.shpsa.2020.09.010. Please quote published version.

Consider the study of CO blobs and color vision by Livingstone and Hubel (1984, 1987, 1988). They showed that blob cells were color-sensitive, whereas cells located between the blobs - in "interblobs" - were orientation- but not color-selective. The researchers also showed that blobs and interblobs connect to different CO stripes that run in parallel throughout area V2. But Livingstone and Hubel (1988) did not use the column concept to describe CO blob and stripe systems. ${ }^{4}$ Instead, they linked them to different visual pathways running from the retina through the lateral geniculate nucleus (LGN) and the visual cortical areas, shown in Fig. 2.

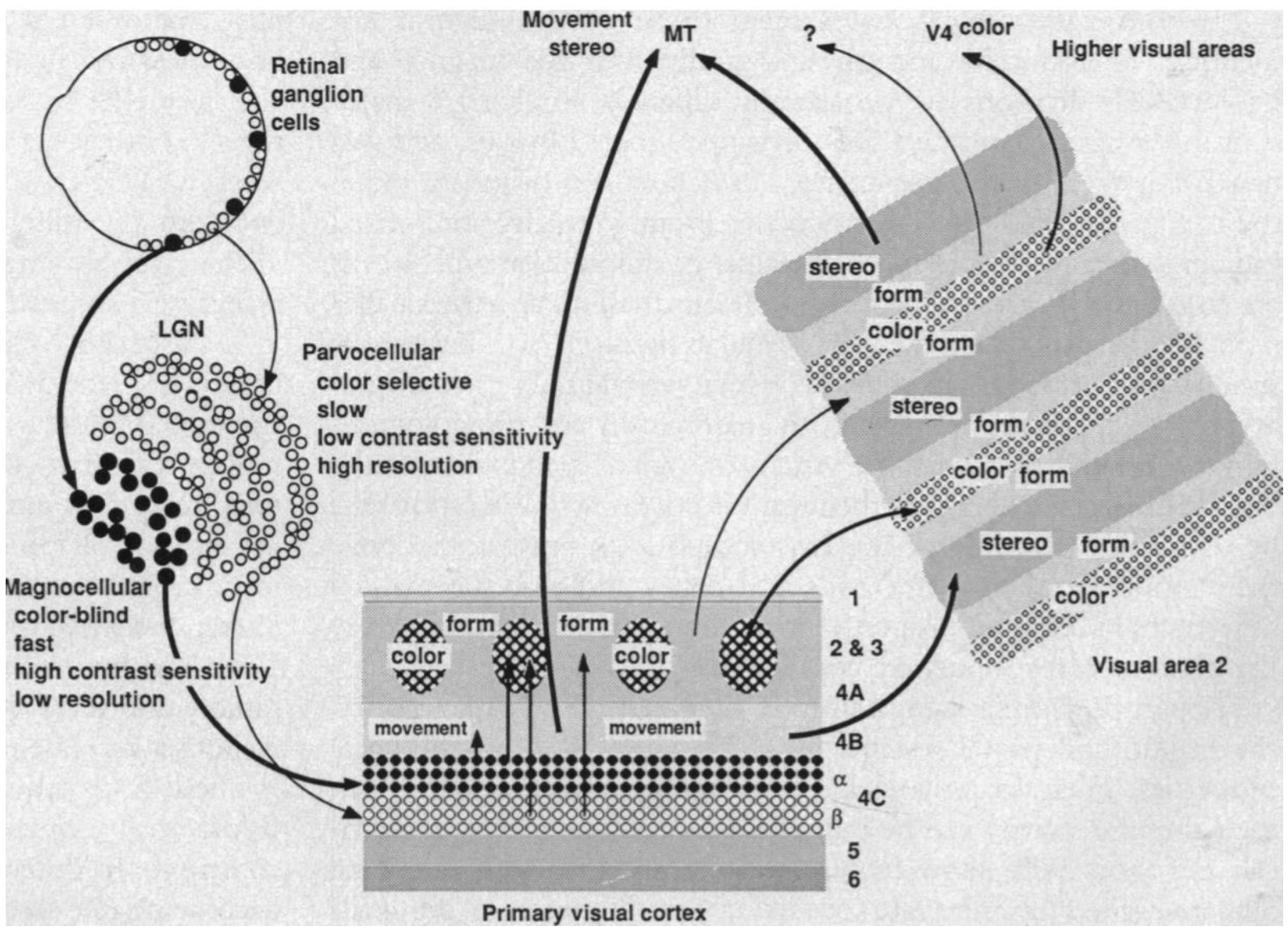

Fig. 2. Diagram of functionally segregated pathways in the visual system (Livingstone and Hubel 1988, Fig. 4).

In Fig. 2, V1 blobs (bottom, middle) and V2 stripes (right) support the segregation of the visual system into a color, movement and form pathway, without mention of V1 hypercolumns. This functional organization supports the MFH view because the blobs and interblobs represent color and form, respectively and feedforward this information to different types of V2 stripes. Livingstone and Hubel used strategies of the MFH view, not the classical columnar outlook to

\footnotetext{
${ }^{4}$ This was a gradual process. The classical columnar outlook was initially supplemented by the CO studies (Livingstone \& Hubel 1984, p. 353; 1987 p. 3428; Hubel \& Livingstone, 1987, p. 3389f., p. 3405). In the 1988 paper, the column concept had disappeared altogether.
} 
Preprint to appear in Studies in History and Philosophy of Science, doi: 10.1016/j.shpsa.2020.09.010. Please quote published version.

explain away problems with Fig. 2. To counter the problem that interblobs were also received input from color-sensitive cells, Livingstone and Hubel (1988) argued that color information is irrelevant to interblob cells because they explicitly represent edges, not color (ibid., p. 744ff.). They could thus explain functional differences within an area by subdividing it into internal compartments (Burnston 2016, fn. 7). Using this strategy from the MFH view, however, did not commit them to the claim that $\mathrm{CO}$ blobs/stripes are columnar units with discrete boundaries.

Third, researchers who continued to use "hypercolumn" explicitly did so without referring to discrete anatomical boundaries. Roe and Ts'o (1995) combined optical imaging and tangential electrode recordings to record how V2 stripes respond to luminance and color stimuli. ${ }^{5}$ They concluded that V2 stripes contain hypercolumns for processing color, orientation and disparity. This use of the column concept, however, is quite distinct from the classical columnar outlook. Roe and T'so (1995, p. 5713) argued that the ice cube model (Fig. 1b) misleadingly suggests that "hypercolumn" refers to modules of a specific spatial shape and discrete anatomical boundaries (C1). Instead, they emphasized that the concept refers to activities that map all functional input variables within an areal subdivision, regardless of the specific shape of that subdivision. By applying "hypercolumn" to V2, Roe and T'so shift the significance of that concept away from its initial meaning, which now appears misleading. But this shift also implies that in higher visual areas, "hypercolumn" does not refer to the kind of anatomical modularity observed in ocular dominance columns and or posited for somatosensory columns (Hubel \& Wiesel, 1977; Mountcastle, 1978).

\subsection{Challenge 2: Functional diversity and non-columnar response patterns}

The second challenge to the classical columnar outlook is that researchers found cortical areas in which columns showed functionally diverse responses and a complex, non-columnar functional architecture. In the following I describe research in two such areas: middle temporal area (MT) and primary auditory cortex (A1).

Experiments on visual area MT revealed that columnar patterns are just one form of functional architecture in the neocortex. MT was traditionally considered to be a motion-processor, because its cells selectively respond to the axis or direction in which stimuli move (Burnston 2016). Albright, Desimone, and Gross (1984) tested whether axis of motion and direction-se-

\footnotetext{
${ }^{5}$ Optical imaging signals measure increases in deoxidized hemoglobin in the capillaries, which is assumed to trace nearby neuronal activity relates to the stimulus (Tanaka 1996, p. 124).
} 
Preprint to appear in Studies in History and Philosophy of Science, doi: 10.1016/j.shpsa.2020.09.010. Please quote published version.

lectivity were organized in columnar systems. They could not straightforwardly apply the column concept, however, because the curvature of MT prevented vertical electrode recordings. In the single-unit recordings they were able to perform, Albright et al. (1984, Fig. 5) found that the sequence regularity of direction-selective cells ranged from perfect to chaotic. Because they were furthermore "unable to detect discrete, uniform changes in axis or direction of motion preference" (ibid., p. 29) they had to estimate column sizes by fitting regression lines through the recorded sequence shifts (cf. ibid., p. 23). They estimated $400-500 \mu \mathrm{m}$ as the minimal hypercolumn size for a $180^{\circ}$ shift of direction selectivity, with cells responding to opposite directions lying in the same axis of motion column. The results also left the geometry of the columns system completely open: "columns of directionally selective cells could exist as discrete islands and could be arranged either regularly or randomly within a single axis of motion slab" (ibid., p. 29). The utility of the classical columnar outlook for understanding MT's functional organization was thus limited.

The usefulness of the column concept was further complicated when researchers discovered that MT responds not only to direction, but also to the disparity of a stimulus. ${ }^{6}$ DeAngelis and Newsome (1999) combined combining single- and multi-unit recordings which showed that disparity-tuning in MT was distributed in a non-columnar fashion. Unlike the variables of ocular dominance and orientation tuning, direction and disparity tuning are not significantly correlated (cf. ibid., p. 1410). Disparity-selective cells form patchy "islands" surrounded by weakly tuned cells, as shown in Fig. 3:

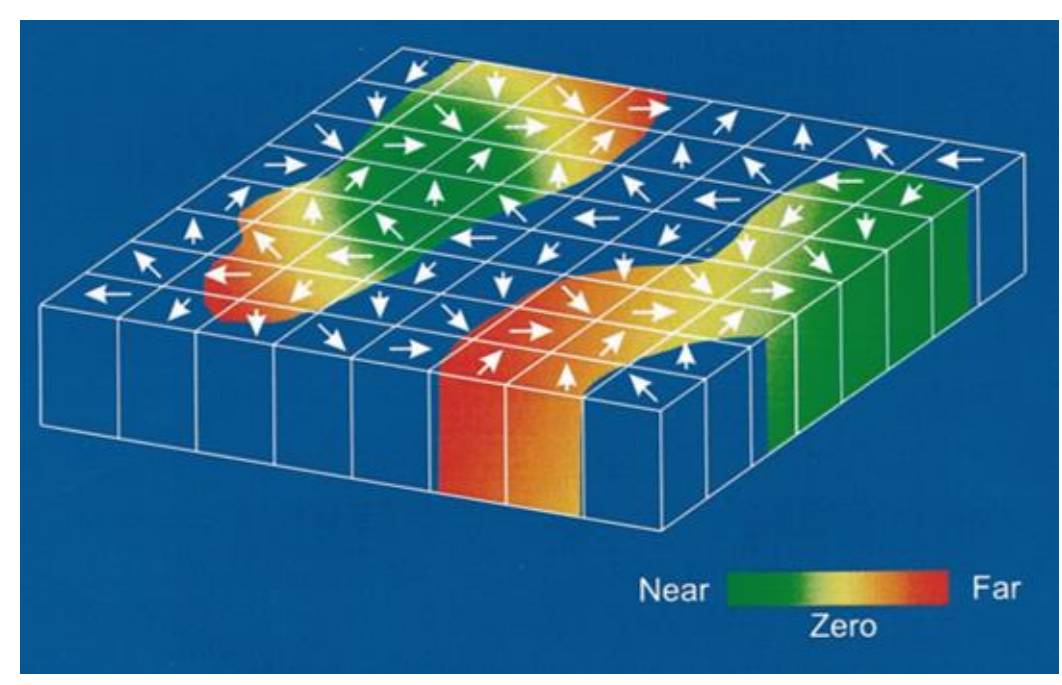

Fig. 3. Functional architecture of MT. While all MT cells are orientation-selective (white arrows), some are only weakly disparity selective (dark blue regions).

\footnotetext{
${ }^{6}$ Disparity refers to the difference in angles at which light hits the two eyes. Different kinds of disparity are important cues for different kinds of depth perception (cf. Burnston 2016, 537f.).
} 
Preprint to appear in Studies in History and Philosophy of Science, doi: 10.1016/j.shpsa.2020.09.010. Please quote published version.

Fig. 3 shows that direction and disparity are not organized into orthogonally positioned functional columns. Yet, DeAngelis and Newsome continued the graphical convention of the icecube model when displaying their results. But like Albright et al. (1984), they also admitted that the sharp boundaries separating cells with different direction tunings "should not be taken literally" (ibid., p. 1412).

In contrast to MT, researchers had already suggested in the 1960s and 70s that primary auditory cortex (A1) exhibits a columnar organization (reviewed in Mountcastle, 1978). As in V1, two columnar systems were posited: one for frequency-selective responses and one for responses to input from the two ears (binaural interaction). Starting in the 1980s, however, two assumptions for applying the column concept to A1 came under critical scrutiny. First, Phillips and Irvine (1983) argued that the classification of A1 neurons into summation columns and suppression columns concealed the true functional diversity of binaural interaction. ${ }^{7}$ Their single-cell recordings revealed cells that did not belong to either category. They also showed that cells in the same column exhibit different types of binaural interaction. Phillips and Irvine therefore concluded that "columns defined by one or other interaction type may contain binaurally diverse elements involved in different kinds of stimulus processing" (ibid., p. 393). Their results thus challenge (C2), i.e. that cells in one column have uniform, rather than categorically distinct functional response properties. Second, Reser et al. (2000) argued that the use of anesthetics supresses sustained inhibitory and excitatory responses to auditory stimuli. Using micro-electrode arrays to record auditory responses in behaving macaques, they found signal components indicating binaural summation that extended far beyond columnar boundaries. These responses only occurred in layers 3 and 4, suggesting that binaural interaction is not organized radially throughout $\mathrm{A} 1 .^{8}$

Besides methodological limitations, there are also anatomical and functional differences between V1 and A1 which challenge the classical columnar outlook. A1 receives binaural inputs from four subcortical nuclei whereas V1 primarily receives monocular input from LGN (Linden \& Schreiner 2003, p. 83f.). In A1, only the excitatory receptive fields in layers 3 and 4 inherit the receptive field properties of the auditory thalamus, whereas V1 cortical cells in layer 4 inherit both inhibitory and excitatory receptive fields from multiple LGN cells (cf. ibid., p.

\footnotetext{
${ }^{7}$ In summation columns, binaural responses are stronger than monoaural responses. Suppression columns show the opposite pattern.

${ }^{8}$ Non-columnar responses in unanesthesized animals also occurred in other areas, e.g., in parietal cortex while macaques performed goal-directed behavior (Mountcastle, Lynch, Georgopoulos, Sakata, \& Acuna, 1975, p. 903).
} 
Preprint to appear in Studies in History and Philosophy of Science, doi: 10.1016/j.shpsa.2020.09.010. Please quote published version.

85). Linden and Schreiner argue that the observed non-columnar response patterns in A1 arise from these differences in the mechanistic organization between V1 and A1. The complex functional architecture of A1 is shown in Fig. 4:

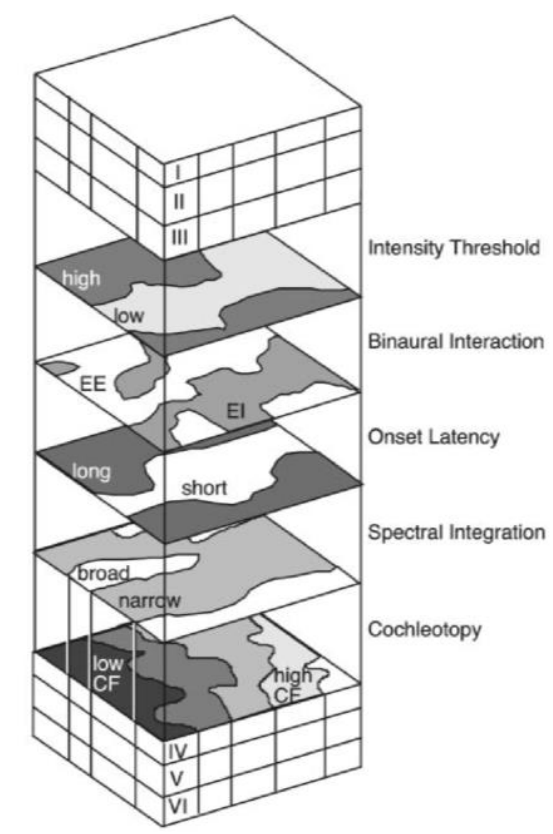

Fig. 4. Overlapping feature maps in A1. Adapted from Linden and Schreiner (2003).

Figure 4 shows that in those layers which receive thalamic input, A1 contains four other functional maps besides the frequency selectivity and binaural interaction. It is unclear whether these maps exhibit columnar organization.

\subsection{Challenge 3: Horizontal connections and the intrinsic function of minicolumns}

In this section, I first show that the classical columnar outlook continued to be successful in the study of columnar microanatomy, since it provided strategies to reinterpret evidence against the anatomical modularity of columns and minicolumns. I then describe why the closer study of horizontal connections in the mid 2000s revealed that minicolumns have no discrete boundaries, which challenges the view that they are autonomous units computing an intrinsic function $(\mathrm{C} 3)$.

In contrast to Hubel's switch to blobs, processing pathways and the psychophysics of color vision, Wiesel continued to focus on columns in V1, especially their intrinsic connectivity. To adequately describe columnar microanatomy, Wiesel and Gilbert (1983) used two novel experimental techniques: intracellular recordings and horseradish peroxidase stains. Combined with the analysis of receptive fields, they could now relate functional descriptions of neurons 
Preprint to appear in Studies in History and Philosophy of Science, doi: 10.1016/j.shpsa.2020.09.010. Please quote published version.

to their full dendritic and axonal branching pattern. Wiesel and Gilbert applied this protocol to cat V1 cells and summarized the results in a wiring diagram (ibid., Fig 2). In this diagram, cells from the $\mathrm{X}$ - and Y-pathway in the LGN terminate onto simple cells in layer 4C and 4A/4B respectively, although it was unclear whether they converge in the superficial layers $2 / 3$. Complex cells in the superficial layers connect to cells in deep layers 5 and 6, and layer 6 cells project back to layer 4 .

In addition to confirming Hubel and Wiesel's wiring scheme for layers 2-4, Wiesel and Gilbert (1983) also found cells in layer 5 whose axons horizontally project far outside orientation column boundaries and deep into layer 6 . The discovery of these horizontal connections, however, did not immediately challenge the anatomical modularity of orientation columns. Wiesel and Gilbert successfully used strategies of the classical columnar outlook to explain away non-columnar evidence in V1, similar to how Livingstone and Hubel used strategies of the MFH view to resolve anomalous results in the interblobs (section 2.1). Because layer 5 cells have the same orientation as other cells within the column, their horizontal connections must also target columns with the same orientation, such that they sum input over a larger visual field position than either of the individual columns (ibid., p. 532). As shown in Fig 5a. below, long horizontal connections $(6-8 \mathrm{~mm})$ preferentially connect to areas with similar orientation selectivity. In order to account for column specificity, Wiesel and Gilbert (1983) additionally argued that horizontal projections in layers $2 / 3$ target cells that produce inhibitory flanks in complex receptive fields_-what Mountcastle (1978, p. 32) had called "pericolumnar inhibition". Recurrent connections from layer 6 cells to layer 4 could produce end-inhibition that causes simple cells to be selective for edges of a restrictive length (Wiesel \& Gilbert, 1983, p. 533, 538).

Wiesel and his co-workers also used strategies from the classical columnar outlook when investigating the microanatomical boundaries of ocular dominance columns in the macaque visual cortex. Using fluorescent tracers to label these structures after ocular dominance was determined via electrode recordings, Katz et al. (1989) used hippocampal slice chambers to fill layer $4 \mathrm{C} \beta$ neurons with Lucifer yellow stain. These in vitro experiments showed that the dendrites of smooth or sparsely spined stellate cells do not cross ocular dominance borders, while axons do cross these borders. Cells with bodies close to or directly on the border connect to both columns equally. To account for these findings within the columnar outlook, the researchers picked up on the idea of transition zones that Hubel and Wiesel had abandoned in favor of the binary grouping of ocular dominance into columns (Haueis 2016). While Katz et al. (1989, p. 1393) estimated that up to $40 \%$ of cells could lie within those transition zones, they also 
Preprint to appear in Studies in History and Philosophy of Science, doi: 10.1016/j.shpsa.2020.09.010. Please quote published version.

argued that their dendritic bias could reduce the input from the neighboring column, and that a putative pericolumnar inhibition mechanism could abolish it altogether. They even claimed that previously recorded functional discontinuities implied that the cells with bodies on the border must have dendritic fields that split inputs between both eyes (cf. ibid. p. 1395). So rather than admitting that such cells are binocularly driven, they pushed the splitting strategy to subcellular components to apply the ocular dominance column concept to these borderline cases.

Until the mid 2000s, microanatomical research did not challenge the classical columnar outlook because horizontal connections were assumed to be weak in comparison to the strong vertical connections within columns (Mountcastle, 1997, Fig. 16), because they were observed to connect columns with the same stimulus-selectivity (Das, Bennett, \& Gilbert, 2002) and because pericolumnar inhibition was supposed to abolish activity across column boundaries. The microanatomical research thus seemed to further support Mountcastle's view that minicolumns are autonomous vertical modules which compute the same intrinsic function across the mammalian neocortex (C3). This situation changed, when new neuroanatomical data on minicolumns became available in the mid 2000s. Fig. 5a shows that within a 500 $\mu$ m radius, cells from one orientation column have strong horizontal connections to cells of all orientation preferences. Fig. 5b shows that dendrites of one anatomical minicolumn equally extend beyond several minicolumns. In cat cortex, $92 \%$ of the synapses within a minicolumn come from cells further than $100 \mu \mathrm{m}$ away (da Costa and Martin 2010, p. 6). It is unclear how minicolumns can form autonomous vertical modules computing the same intrinsic function, given that each minicolumn connects horizontally to many other cells outside a $30 \mu \mathrm{m}$ radius.

a
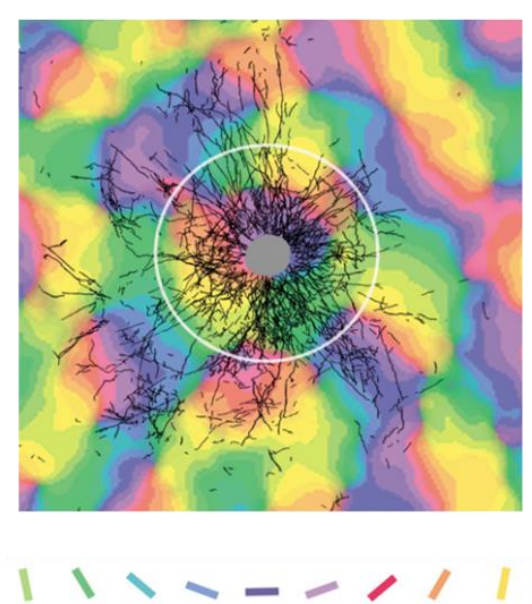

b

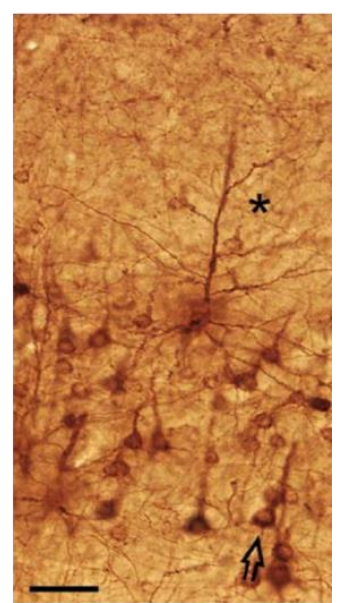

Fig. 5. a. Labeled axons (black lines) of cells (grey dot) in superficial layers of V1, superimposed on a color-coded orientation preference map generated from optical imaging data. Adapted from Stettler, Das, Bennett, \& Gilbert, (2002), Fig. 7A. Axons beyond 500 $\mu \mathrm{m}$ from the injection site (white circle) target patches with similar orientation (purple colors). b. Retrogradely filled neurons in V2 show that dendrites (asterisk) extend beyond multiple vertical cell bands (black arrow). Adapted from Rockland \& Ichinohe (2004), Fig. 6D. 
Preprint to appear in Studies in History and Philosophy of Science, doi: 10.1016/j.shpsa.2020.09.010. Please quote published version.

In sum, research between 1981 and 2005 challenged the view that "cortical column" refers to anatomically discrete $(\mathrm{C} 1)$ functional modules $(\mathrm{C} 2)$ with a common intrinsic function across the entire mammalian neocortex (C3). These limitations extend to other cases. Consider columns in inferotemporal cortex (IT), a textbook example of applying the column concept. Neuroscientists use "cortical column" to describe IT without referring to discrete anatomical boundaries (Tanaka, 1996, p. 136). Rather they describe functional hypercolumns that are situated along the processing hierarchy of the ventral visual pathway (ibid., p. 125). This use of "cortical column" is consistent with the MFH view but dissociable from the classical columnar outlook (section 2.1). Similarly, the boundaries between larger units of columns depend on the choice of critical stimuli, which raises the problem of stimulus categorization discussed in section 2.2 (Tanaka, 2003, p. 91). Finally, horizontal connections link IT neurons with functionally diverse response properties (Tanigawa et al., 2004), which cahllenges the intrinsic function view of minicolumns. Thus, the case of IT further supports my claim that most uses of "cortical column" after 1981 challenge the classical columnar outlook.

\section{The patchwork structure of "cortical column"}

\subsection{A patchwork model of the column concept}

Despite the challenges to the classical columnar outlook, neuroscientists continued to use central terms (“minicolumn”, “column”, “hypercolumn”), experimental techniques (vertical/tangential electrode recordings, histological staining techniques), generalizations (sequence regularity), and diagrammatic conventions (ice-cube model) from the classical columnar outlook to conceptualize their results. The reason for this continuity is that after 1981, the classical columnar outlook became part of a much larger patchwork of local uses of the column concept. I call these local uses the different patches of the column concept. In the following, I analyse six such patches: the minicolumn, column and hypercolumn patch, the $\mathrm{CO}$ blob/stripe patch, the barrel patch and the ontogenetic column patch. Each of these patches is characterized by the experimental techniques used to apply "cortical column", the scale-dependent property of columns detected by these techniques, and the domain of entities which have these scale-dependent properties.

First, column patches involve specific experimental techniques which instruct researchers how to use a measurement procedure to achieve a specific kind of experimental outcome 
Preprint to appear in Studies in History and Philosophy of Science, doi: 10.1016/j.shpsa.2020.09.010. Please quote published version.

(Colaço, 2018, p. 7). The classical columnar outlook instructs researchers to use three experimental techniques: (i) histological staining techniques (e.g., Golgi and Nissl stain, NautaHeimer method) to establish that columnar structures have discrete anatomical boundaries (C1), (ii) vertical electrode recordings to establish uniform functional responses within a column (C2) and (iii) tangential recordings to establish that these responses change abruptly and are sequence regular across multiple columns (C2). Section 2 showed that column researchers also use many other experimental techniques, producing results that challenge $(\mathrm{C} 1)-(\mathrm{C} 3)$. For example, the $\mathrm{CO}$ blob/stripe patch instructs researchers to use $\mathrm{CO}$ staining to reveal functional modules without referring discrete anatomical boundaries (section 2.1).

Second, column patches are scale-dependent because different experimental techniques target columnar structures at different scales: minicolumns at the microscale of individual cells $(\sim 30-80 \mu \mathrm{m})$, columns at the mesoscale of neural circuits $(\sim 500 \mu \mathrm{m})$ and hypercolumns at the macroscale of cortical areas ( 1-2mm). Each scale is associated with a characteristic structural or functional property (cf. Bursten, 2016): strong vertical and weak horizontal connections (minicolumn patch), uniform functional responses (column patch) and sequence regularity (hypercolumn patch).

Third, column patches specify a domain of entities with a scale-dependent functional or structural property. The scope and number of domains has to be determined empirically (Novick, 2018, p. 6). For example: the domain of columns includes V1 circuits but not A1 circuits because former show uniform functional responses whereas the latter show functionally diverse responses when researchers apply vertical electrode recordings. Similarly, the domain of hypercolumns includes sequence regular responses in the entire area V1 and V2, but only responses in some parts of area MT, where sequence regularity ranges from perfect to chaotic. Finally, the domain of minicolumns is supposed to include vertical neuron bands in the entire cortex, provided that these bands have vertical connections which are stronger than their horizontal connections.

Column patches form a patchwork structure because they are systematically related to one another. One way to link column patches together is by reusing experimental techniques from one patch to explore columnar structures at other scales or novel domains. For example: tangential recordings can be used to detect uniform functional responses (column scale) or to establish that these responses are sequence regular (hypercolumn scale). Similarly, CO staining technique can be reused across domains to detect CO blobs in V1 and CO stripes in V2. Another way to link column patches is to combine results from multiple patches in an inference about 
Preprint to appear in Studies in History and Philosophy of Science, doi: 10.1016/j.shpsa.2020.09.010. Please quote published version.

functional architecture. For example: the ice-cube model in Fig. $1 \mathrm{~b}$ combines four results to draw an inference about the functional architecture of V1: orientation-selective responses (minicolumn patch) and their sequence regularity (hypercolumn patch), and the anatomical uniformity of ocular dominance columns (column patch) and CO blobs (CO patch). Note that this is a material inference: its validity depends on facts about its subject matter (here: facts about V1), rather than on the formal structure of the inference schema (cf. Love, 2013, p. 330). The patchwork model thus describes the material inferential structure of the column concept: it explicates the relations between different scale-dependent, technique-involving and domainspecific uses of "cortical column. ${ }^{9}$ The patchwork structure of the column concept is visualized in Fig. 6.

\footnotetext{
${ }^{9}$ Unlike Love, I ascribe a material inferential structure to a concept, not a theory. The reason is that the column concept originated from exploratory experiments, without researchers having a theory of the cortex (Haueis, 2016). Wilson (2006), Novick (2018) and Haueis (2018) and Burnston and Haueis (2020) also develop patchwork models of concepts rather than theories.
} 


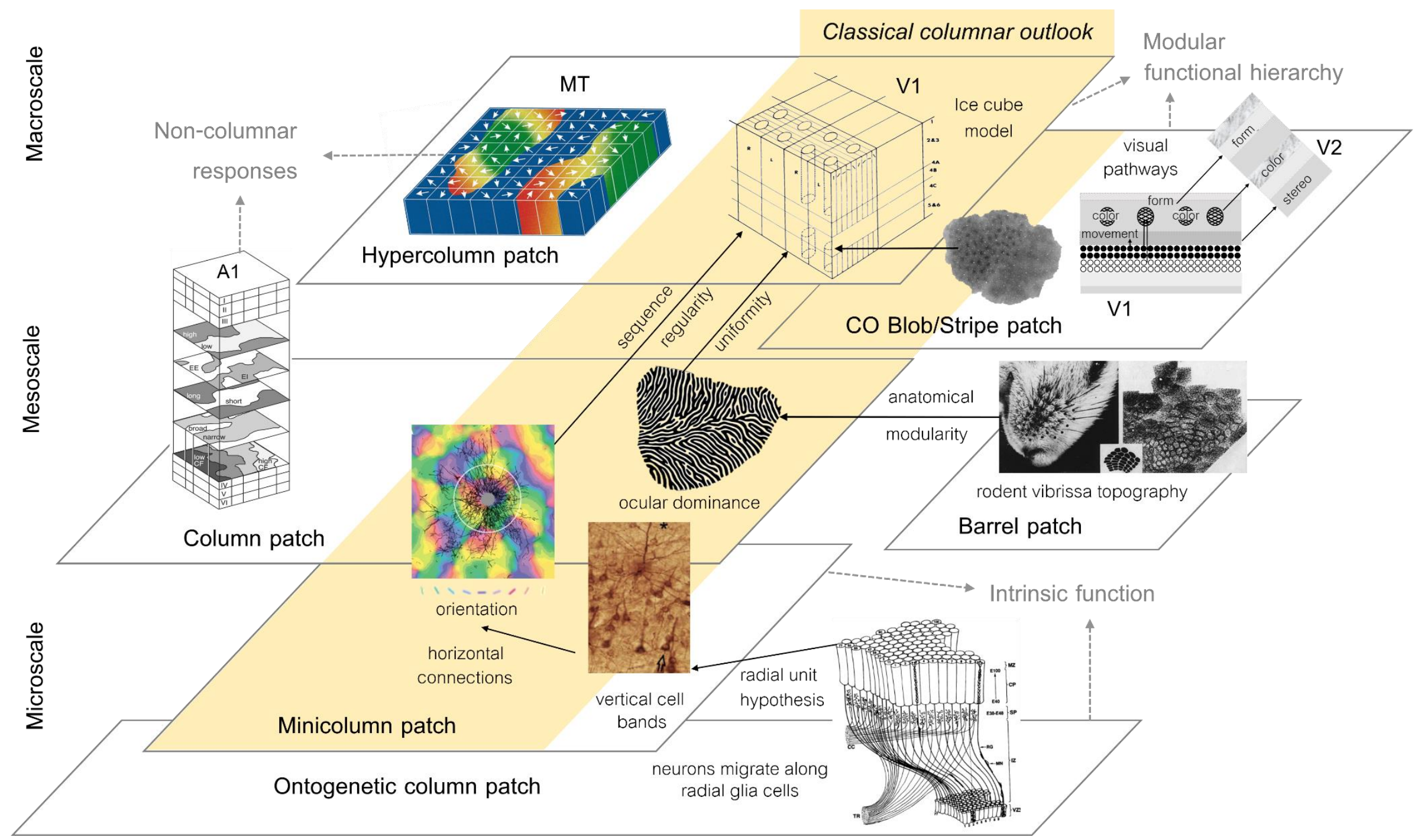

Fig. 6: Patchwork model of the column concept. Figure references as in Figs. 1-5. Additional images: ontogenetic patch: Rakic (1988) barrel patch: Woolsey and van der Loos (1970), ocular dominance: Hubel andWiesel (1977). 
Preprint to appear in Studies in History and Philosophy of Science, doi: 10.1016/j.shpsa.2020.09.010. Please quote published version.

The patchwork model of "cortical column" consists of six patches (grey rectangles) on three scales. It visualizes the relation between column research which led to the classical columnar outlook (Haueis, 2016; yellow shaded regions), the research challenging this outlook (section 2, white regions on minicolumn, hypercolumn and $\mathrm{CO}$ blob/stripe patch), and additional research used to support (C1)-(C3) (ontogenetic column patch, barrel patch, see discussion below). Black arrows display the material inferences which support the building block picture, i.e. the view that "cortical column" refers to anatomically and functionally modular building blocks of the mammalian neocortex. Grey dashed arrows display material inferences that challenge the classical columnar outlook and the building block picture associated with it (section 3.2).

The building block picture is supported by the material inferences inside the yellow region of Fig. 6. Consider first the inference on the minicolumn patch. It states that if vertically connected cell bands connect horizontally in a like-to-like manner, then orientation-selective responses constitute evidence for functional minicolumns in V1. Consider next the two inferences which link the column and hypercolumn patch (Fig. 6, upwards black arrows). The first inference states that if orientation-selective responses are sequence-regular roughly every $1 \mathrm{~mm}$ (Hubel \& Wiesel, 1977, p. 38), then a V1 hypercolumn consists of 8-10 orientation columns (Fig. 1b). The second inference states that if ocular dominance columns are ca. $0.4 \mathrm{~mm}$ wide, anatomically uniform modules across V1 (Hubel \& Wiesel, 1977, p. 38), then a V1 hypercolumn consists of two ocular dominance columns (one for each eye). In the ice-cube, model, ocular dominance and orientation columns are orthogonally position to one another (Fig. 1b). This model also links the hypercolumn patch to the $\mathrm{CO}$ blob/stripe patch by inserting four CO blobs into each V1 hypercolumn (Fig. 1b).

The ice-cube model provides the basis for the building block picture because it entails the following conjunctive relation between three columnar structures and their scale-dependent columnar properties:

(CR) Hypercolumn ${ }^{2-3 m m}$ (sequence regularity) $\wedge$ Column $^{0.5 m m}$ (uniform functional responses) $\wedge$ Minicolumn $^{30-80 \mu m}$ (vertical connections $>$ horizontal connections)

If (CR) is true, then the three scale-dependent properties of cortical columns always occur together in the neocortex. These properties thus constitute a columnar building block whose anatomical and functional modularity allow it to process basic features of a sensory stimulus. To understand why leading neuroscientists around 1980 thought that this building block is repeated 
Preprint to appear in Studies in History and Philosophy of Science, doi: 10.1016/j.shpsa.2020.09.010. Please quote published version.

throughout the entire mammalian neocortex (Mountcastle, 1978; Szenthágotai, 1978; Eccles, 1981), we need to consider the material inferences which link two additional patches to the classical columnar outlook. Consider first the material inference linking the minicolumn and ontogenetic column patch (Fig. 6, black arrow lower right). According to the radial unit hypothesis, bands of neurons - called ontogenetic columns - migrate along radial glia cells during cortical development (Rakic 1988). Mountcastle (1978, p. 11; 1997, p. 705) argued that the ontogenetic columns are identical to functional minicolumns in the adult neocortex. If functional minicolumns are identical to ontogenetic columns, then functional minicolumns are present in the entire neocortex. This ontogenetic-to-minicolumn inference expands the scope of (CR) from V1 to the entire neocortex. Consider now the second material inference, which links the barrel patch to the column patch. Cortical barrels are structures located in layer 4 of somatosensory cortex of rodents. They contain neurons which respond to stimuli of the same whisker hair (vibrissae) and are separated by a walllike region without cell bodies (see image on barrel patch). Mountcastle (1978, p. 19) subsumed barrels under the column concept to support the following inference: if cortical columns in primates are similar to cortical barrels in rodents, then cortical columns are anatomically modular across mammals. Thus, the barrel-to-column inference allowed researchers to expand (CR) across multiple species. By adding the ontogenetic-to-minicolumn and barrel-to-column inference column researchers, the patchwork model reveals how neuroscientists supported the building block picture.

\subsection{From the building block to the diverse-kinds picture of "cortical column"}

While the patchwork model reveals how the building block picture was initially supported, it also shows why it was ultimately faulty. I now argue that we should follow column critics and reject the building block picture in favor of the diverse kinds picture: rather than referring to the same anatomically discrete functional module, "cortical column" refers to diverse kinds of columnar structure whose functional significance varies across species.

There are two sets of problems with the building block picture. The first is that it cannot account for those material inferences that challenge the classical columnar outlook (Fig. 6, grey dashed arrows). Consider first the inference that connects the hypercolumn and CO blob/stripe 
Preprint to appear in Studies in History and Philosophy of Science, doi: 10.1016/j.shpsa.2020.09.010. Please quote published version.

patch to the MFH view (Fig. 6, upper right corner). It states that if hypercolumns and CO blobs are parts of visual pathways, then they process information in an increasingly abstract fashion. This inference dissociates the MFH view from the classical columnar outlook because it does not commit researchers to discrete anatomical boundaries (section 2.1). In a similar vein, column critics write that "[anatomical] modularity per se may be of less general significance to cortical function" than column researchers suppose (Purves, Riddle \& LaMantia, 1992, p. 366). The building block picture conceals that anatomical modularity $(\mathrm{C} 1)$ is not required to explain hierarchical information processing in the visual system.

Next, consider the inference which links the minicolumn and the ontogenetic column patch to the intrinsic function view. It states that if vertical cell bands (a) have strong vertical and weak horizontal connections and (b) are identical to ontogenetic columns, then minicolumns compute the same intrinsic function in the entire neocortex. Researchers from the microanatomical pathway cannot draw this inference because once they account for horizontal connections, they cannot support condition (a) in the antecedent of the inference (section 2.3). Column critics also point out that column researchers "had been mistaken to suppose that neurons within a $30-\mu \mathrm{m}$ column are much more strongly connected than the connections between these cortical columns" (da Costa \& Martin, 2010, p. 6). If vertical cell bands horizontally connect to functionally diverse cells outside a $30 \mu \mathrm{m}$ radius (Fig. 5), then minicolumns are not autonomous functional units. The building block picture conceals that one cannot simultaneously account for horizontal connections within the classical columnar outlook and assume that minicolumns compute an intrinsic function (C3).

Finally, consider the inference from the column and hypercolumn patch to noncolumnar responses (Fig. 6, upper left). It states that if functional responses higher visual and nonvisual areas are diverse or non-columnar, then their functional architecture is not functionally modular (C2). Column critics similarly point out that that anatomical and physiological techniques have not revealed columnar functional architecture: in A1, there is "little evidence of any predominant spatial frequency and no evidence for the existence of a uniformly sized modular subunit" (Swindale, 1990, p. 489). In MT, electrode recordings and CO staining have failed to reveal a hypercolumn in which direction- and disparity selective responses are systematically related (cf. Horton \& Adams, 2005, p. 852). The building block picture cannot account for this limitation of columnar experimental techniques to infer columnar functional architecture in other cortical areas. 
Preprint to appear in Studies in History and Philosophy of Science, doi: 10.1016/j.shpsa.2020.09.010. Please quote published version.

The second problem is that the building block picture cannot account for arguments against the validity of inferences taken to support (C1)-(C3). Consider first the ontogenetic-to-minicolumn inference. Column critics argue that ontogenetic columns are "remnants of foetal development [that] have no known functional relationship to columns in the adult cortex" (Horton \& Adams 2005, p. 839). A common developmental mechanism does not bestow functional significance upon the resulting anatomical modules (Purves, Riddle \& LaMantia, 1992, p. 365; Catania 2002, p. 355). Thus, the functional significance of minicolumns remains unclear even if they are identical with ontogenetic columns.

Consider next the barrel-to-column inference. Catania (2002, p. 348) and Horton and Adams (2005, p. 854) argue that cortical barrels are not cortical columns but cortical isomorphs, i.e. isomorphic representations of structures in the sensory periphery The shape of cortical isomorphs reflects the surface shape from which somatosensory cortex receives input. Cortical barrels in rodents reflect the shape of whisker hair, which are cylindrical. In the star-nosed mole, the respective modular units have a stripe-like shape arranged in the star-like pattern (ibid., p. 350). Therefore, vertically uniform responses in barrels are an artefact of the cylindrical shape of cortical barrels, and not a true sign of cortical columns in rodents.

Finally, consider the species variation of many columnar structures. Orientation columns are found in many mammals but are absent in rats and squirrels, even though these animals have cells that are highly orientation-selective (Horton \& Adams, 2005, p. 843). Racoons, beavers and cats have whiskers but lack barrels, while guinea pigs have barrels but do not show whisking behavior (Horton \& Adams 2005, p. 852). Similarly, ocular dominance columns are present in some primates, but not others, while both have similar visual capacities (Purves, Riddle \& LaMantia, 1992, p. 363). In squirrel monkeys, $30 \%$ of the cases examined by lack ocular dominance structures (Horton \& Adams, 2005, p. 844). In other individuals of the same species, only part of V1 exhibited ocular dominance columns, despite intact vision. These findings challenge the view that ocular dominance columns contribute to the detection of depth cues across the visual field.

If we take the two sets of problems of the building block picture together, we see why the content of (CR) is empirically inadequate and why its scope cannot be the entire neocortex. (CR) is empirically inadequate because it does not reflect that hypercolumns are sequence regular but lack discrete anatomical boundaries, that horizontal connections between minicolumns are equally 
Preprint to appear in Studies in History and Philosophy of Science, doi: 10.1016/j.shpsa.2020.09.010. Please quote published version.

strong or stronger than vertical ones, and that higher visual and nonvisual areas exhibit noncolumnar responses. The scope of $(\mathrm{CR})$ cannot be expanded to the entire neocortex and all mammalian species. The ontogenetic-to-column inference does not warrant the extension of the minicolumn patch to the entire neocortex, because a common developmental mechanism does not guarantee the functional significance of the resulting columnar structures. The barrel-to-column inference does not warrant the extension of the column patch to cortical barrels because these structures belong to the domain of cortical isomorphs, not to the domain of cortical columns. Finally, the inter- and intraspecies variation of columnar structures speaks against the view that cortical columns execute a species-invariant intrinsic function.

Based on these problems, column critics reject $(\mathrm{CR})$ and thus, the building block picture: "the concept of the 'universal cortical column' is very captivating [but] there is no single structure or function that is the common building block of all cortical areas in all mammals" (Molnár 2013, p. 125f.). Rather than referring to the basic building block of the mammalian neocortex, "cortical column" refers to diverse kinds of columnar structure:

it seems misleading to refer to the various columns, hypercolumns, slabs, stripes, strips, bands, barrels, beads, blobs, patches, puffs and lattices that have been discovered in cortex as modules in any but a limited and strictly local sense. (Swindale 1990, p. 492).

I call this the diverse-kinds-picture of "cortical column". This picture replaces (CR) with the following disjunctive relation $(\mathrm{DR})$ :

(DR) Hypercolumn ${ }^{2-3 m m}$ (sequence regularity) $\vee$ Column $^{0.5 m m}$ (uniform functional responses)

$\vee$ Minicolumn $n^{30-80 \mu m}$ (vertical connections $\geq$ horizontal connections)

The patchwork model supports (DR). It holds that different technique-involving uses of "cortical column" target scale-dependent columnar properties that can occur independently of one another. Column patches can refer to one of these properties in one area without referring to the others. Column patches are also domain-specific, i.e. they are indexed to distinct kinds of columnar structures with different scale-dependent functional or structural properties. The scope of each domain depends on how many areas and how many species exhibit the scale-dependent property. Whereas the scope of (CR) include all areas and mammalian species, the scope of each disjunct in (DR) is determined by the scope of the respective domain of the respective column patch. 
Preprint to appear in Studies in History and Philosophy of Science, doi: 10.1016/j.shpsa.2020.09.010. Please quote published version.

The patchwork model agrees with the column critics that we should reject the building block picture and embrace the diverse-kinds-picture. There is no general definition of "cortical column" which subsumes every technique-involving, scale-dependent use of "cortical column". Rather, there are multiple, equally legitimate uses of this concept which pick out different kinds of columnar structure. None of these kinds is the basic building block of the neocortex in all mammals, and none computes an intrinsic function that is common to every neocortical area. The utility of the column concept is not to identify a common building block, but to help researchers classify the diversity of columnar structure and understand their relations to each other.

\section{Conceptual retirement of the column concept (2005 -today)}

\subsection{Why the column concept should not be eliminated}

Once we acknowledge that "cortical column" has multiple different uses and no general definition, shouldn't we get rid of the superordinate column concept altogether? This is exactly what eliminativists like Taylor and Vickers (2017) argue. They hold that we should eliminate a superordinate concept like "cortical column" in favor of the more precisely defined subconcepts or patches such as "hypercolumn" or "minicolumn". Elimination avoids two risks (cf. ibid. p. 28): (1) the greater the number of epistemic goals a term contributes to, the more different meanings the term acquires and thus the greater the risk of miscommunication becomes; (2) if the concept plays a pivotal role in reaching the conclusions of an argument, the greater the risk of pointless debate that rests on different understandings of the term. The use of "cortical column" seems to raise both risks. First, the column concept contributes to many epistemic goals: it is used to study cortical structure (e.g. ocular dominance columns or vertical cell bands), cortical function (e.g., sequence regularity or hierarchical processing in hypercolumns) or cortical development (e.g., ontogenetic columns). The proliferation of different meanings in these different research contexts can easily lead to confusion (Rakic, 2008; Molnár, 2013). Without clear definitions, researchers may miscommunicate their findings using the term "cortical column", even though they actually study related but subtly different entities, such as cortical barrels (section 3.1). Eliminating "cortical column" would avoid this form of miscommunication. Second, the column concept could also lead to pointless debate because the debate about the functional significance of cortical columns is affected by what is 
Preprint to appear in Studies in History and Philosophy of Science, doi: 10.1016/j.shpsa.2020.09.010. Please quote published version.

meant by "cortical column". If "cortical column" refers to a building block with a common intrinsic function, then species variation of columnar structures seems to suggest that "that the column may have no function" (Horton \& Adams, 2005, p. 837). But if "cortical column" refers to diverse kinds of columnar structure, then species variation may imply that "columnar structures that have no function in some species may acquire a function in others through evolution" (ibid, p. 856). It seems that once we eliminate "cortical column" we can avoid the debate about the function of cortical columns.

I hold that once we adopt the patchwork model of "cortical column", we can avoid miscommunication and pointless debate without having to eliminate the superordinate column concept. First, it is unclear whether trained electrophysiologists and neuroanatomists really risk miscommunication when using "cortical column". As Rakic (2008, p. 12099) points out, "the term "column" is used in so many ways that it can be very confusing to the non-specialist". In contrast to the non-specialist, however, neuroscientists are trained to use "cortical column" in a context-sensitive manner. That training consists in learning how to use a particular experimental technique and knowing the domain in which that technique reliably detects a scale-dependent columnar property. For example: if an electrophysiologist has the goal to use "cortical column" to study function , she is trained to use the column patch by learning that vertical electrode recordings reliably detect uniform functional responses in primary somatosensory cortex but not in primary auditory cortex. By contrast, if a neuroanatomist uses "cortical column" to study development, she is trained to use the ontogenetic column patch by learning that $\left[{ }^{3} \mathrm{H}\right]$ thymidine autoradiography reliably detects the production of vertical cell bands in the developing monkey cortex (Horton \& Adams, 2005, p. 840). Neuroscientists avoid miscommunication by learning the limits of each column patch, e.g. that uniform functional responses do not imply anatomically modular structures, or that developmental evidence does not establish the functional importance of vertical cell bands (section 3.2). Thus, the threat of miscommunication disappears once we acknowledge that neuroscientists learn to use "cortical column" in a technique-involving, scale-dependent and domain-specific manner. Patchwork approaches to scientific concepts hold that such local uses direct scientists in different subfields of the discipline to the most useful and reliable information for the epistemic goal at hand (Bursten 2016, Wilson 2017, ch. 1). So rather than leading to miscommunication, keeping the 
Preprint to appear in Studies in History and Philosophy of Science, doi: 10.1016/j.shpsa.2020.09.010. Please quote published version.

superordinate column concept may actually allow communication amongst neuroscientists working in different subfields. ${ }^{10}$ Even if it does not refer to a common building block, "cortical column" allows electrophysiologists, neuroanatomists and developmental neuroscientists to communicate about how structure, function and development of the neocortex are related, and which methods can and cannot help to integrate these subfields.

The patchwork model furthermore suggests that the debate about functional significance of cortical columns is not pointless. It rather shows why we should switch from the building block to the diverse-kinds picture of "cortical column". The building block picture misleadingly suggests that "cortical column" refers to a common function across the mammalian neocortex. But as shown in section 3.2, this picture is faulty because it does not account for the challenges to the classical columnar outlook and empirical issues with the material inferences that support the expansion of (CR). Hence, we should reject the building block picture and embrace the diverse-kinds picture. The diverse-kinds picture does not suggest a common function because different kinds of columnar structure can vary in their functional significance between areas and species. The diverse-kinds picture is not faulty because it can successfully account for the domain-specificity and species variation of columnar structures. Hence we should interpret Horton and Adams (2005) as rejecting the building block picture when they write that the column may have no common function (ibid., p. 837) and as embracing the diverse-kinds picture when they suggest that columnar structures can be nonfunctional in some species and functional in others (ibid., p. 856). Rather than calling for elimination, the debate about columnar function calls for discarding the faulty building block picture and replacing it with the successful diverse-kinds picture. Patchwork approaches to scientific concepts hold that conceptual progress in science consists in discarding such faulty semantic pictures and replacing them with better ones (Wilson, 2006; Haueis, 2018; Burnston and Haueis, 2020).

Taylor and Vickers (2017) could agree with these responses and insist that it is still better to eliminate "cortical column" in favor of the different column patches. They could point out that neuroscientists in the past did miscommunicate (e.g. in the barrel case) and did mistakenly posit a common function for all columnar structures. By contrast, "eliminativism [...] is fool-proof when it comes to avoiding these worries: it is impossible to talk past one another regarding term ' $\mathrm{x}$ ', or

\footnotetext{
${ }^{10}$ I thank Javier Suárez Díaz for pointing out this integrative role of superordinate categories.
} 
Preprint to appear in Studies in History and Philosophy of Science, doi: 10.1016/j.shpsa.2020.09.010. Please quote published version.

to have a verbal dispute about ' $x$ ', if ' $x$ ' has been eliminated" (ibid., p. 30) Thus, if neuroscientists want to avoid these risks in the future, they should eliminate "cortical column" and talk directly about different kinds of columns such as ocular dominance columns or orientation columns. Not only are these columnar kinds precisely defined, but also can neuroscientists everything they want to say about columns using column patches (cf. ibid., p. 33, where Taylor and Vickers make the same point with regard to the patchwork concept "hardness").

My response is that this reply (a) overestimates the precision of column patches and (b) overlooks the patchwork structure of the column concept. First, as Molnár (2013, p. 113) points out, "structural, functional and embryological definitions [of "cortical column"] are used loosely, and there is a lack of proper and unequivocal definitions". The risk of miscommunication can simply re-occur for each patch when different researchers use "ontogenetic column" or "hypercolumn" etc. in different ways. If this is the case, it is unclear whether anything is gained by eliminating the superordinate column concept in favor of column patches. Second, elimination overlooks that the different column patches are systematically related to one another. These relations have epistemic virtues, i.e. they tell researchers that they can reuse experimental techniques to investigate different scale-dependent properties of cortical columns, e.g. uniform functional responses and sequence regularity. The relation between scale-dependent properties can furthermore be informative about the functional architecture of the neocortex, e.g., that sequence regular orientation columns and uniform ocular dominance columns are orthogonally positioned to one another. Researchers should keep the superordinate category "cortical column" to signify that the scale-dependent properties described by column patches are related to one another.

My reply points out under which conditions the patchwork model supports elimination. If all of the relations linking patches are defeated, then we would have reason to eliminate "cortical column". In this case, the structure between patches would break apart and leave researchers with several distinct patches. But although many of the relations turned out to be empirically problematic (section 3.2), it is not the case that all the relations within the column patchwork were defeated. So rather than eliminating the superordinate column concept, researchers should reconceptualize specific patches whose relation to the column patchwork is problematic. For instance, they should not extend the column patch to cortical barrels because they are cortical isomorphs, not columns. Similarly, they should rethink the notion of minicolumns since vertical cell bands have strong 
Preprint to appear in Studies in History and Philosophy of Science, doi: 10.1016/j.shpsa.2020.09.010. Please quote published version.

horizontal connections and do not show discrete functional responses. Column researchers can implement these conceptual revisions while keeping the superordinate column concept.

A final worry about keeping "cortical column" is that it is invariably associated with the building block picture. The continued use of the term will carry unwanted connotations about a basic functional unit. I think that this worry concerns the neuroscientific use of the term "module", which is sometimes used interchangeably with "column" (Mountcastle, 1997). Column critics attack the idea that the cortex is modular, i.e. composed of iterated building blocks (Purves, Riddle \& LaMantia, 1992). Thus, we should eliminate "module", not "cortical column":

Not only does it seem wrong to describe the cortex as modular, use of the term obscures the real complexity of cortical organization and fails to do justice to the diversity of forms of columnar order that are actually present (Swindale 1990, p. 492).

Once we accept the diverse-kinds picture, we can keep "cortical column" to refer to the kinds of columnar structure, without connotations about a basic functional unit.

\subsection{Conceptual retirement of the column concept}

Although the patchwork model suggests that we should not eliminate but keep "cortical column", the column critics point out serious limits of the column concept. I propose that these limits imply that "cortical column" has reached the phase of conceptual retirement. By 'retirement' I do not mean that the column concept has come to an end and has lost all its utility (which would be a reason to eliminate it). The sense of 'retirement' relevant here is the change of normative authority that occurs when a person retires from their professional position. By retiring, a professional permanently looses their institutional role. As a consequence the speech acts of a retired professional are no longer normatively binding. For example: a retired politician can no longer propose a law, a retired teacher can no longer give marks to her students, and a retired judge cannot sentence anyone to be guilty. But that does not mean that the knowledge of retired professionals is completely useless. An active politician may ask a retired one for advice on a difficult policy decision, a retired teacher can criticize the curriculum of her successor, and a retired judge may write an oped piece on a current court case. These speech acts are not normatively binding to the current practitioners. But they can nevertheless provide guidance or a cautionary tale to avoid the errors 
Preprint to appear in Studies in History and Philosophy of Science, doi: 10.1016/j.shpsa.2020.09.010. Please quote published version.

of past practitioners. Retired professionals can fulfil these subsidiary guiding roles independently of their lack of normative authority.

I suggest that analogously, a concept reaches retirement if it permanently fails to contribute to the central epistemic goal for which it was created, while still being useful to subsidiary guiding roles that are independent of that central goal. The failure to achieve the central goal changes the normative authority of the research associated with the retired concept: while researchers can use it for guidance and as a cautionary tale in ongoing research, they are no longer normatively bound describe the results of this research in terms of that concept. Characterizing a concept as being in conceptual retirement allows a more fine-grained and specific analysis of its normative status than the categorical judgment of being useful/not useful that is often characterizes debates about eliminating a concept (for examples, see Taylor \& Vickers, 2017, p, 23-28).

Let us now apply this characterization of conceptual retirement to "cortical column". Both its proponents and its critics agree that the central epistemic goal of the column concept was to find the building block of the mammalian neocortex (Mountcastle, 1957; 1978; 1997; Swindale 1990, Purves, Riddle \& LaMantia, 1992; Catania, 2002; Horton \& Adams, 2005). According to the patchwork model, the column concept has permanently failed to achieve this epistemic goal because the building block picture of "cortical column" is faulty (section 3.2). ${ }^{11}$ This means that researchers are no longer normatively bound to interpret the discovery of novel functionally modular responses or anatomically modular structures as evidence for a building block of the mammalian neocortex. Additionally, retirement implies that neuroscientists today do not have to accept columnar descriptions of functional architecture as adequate. For example: because of the lack of discrete functional responses at the minicolumn scale, researchers now speak of "orientation maps" rather than "orientation columns" (Swindale, 1990; Yacoub, Harel \& Ugurbil, 2008).

This lack of normative authority does not mean, however, that the column concept is completely useless. Researchers often want to selectively maintain empirical knowledge from parts of

\footnotetext{
${ }^{11}$ This connection only holds in this particular case because the patchwork model supports the diverse-kind, but not the building block picture. In general, a concept can reach retirement without having a patchwork structure, simply by failing to achieve its central epistemic goal. Conversely, a concept can have a patchwork structure and not be in retirement.
} 
Preprint to appear in Studies in History and Philosophy of Science, doi: 10.1016/j.shpsa.2020.09.010. Please quote published version.

the column patchwork while rejecting commitments from the classical columnar outlook. Horton and Adams (2005), for instance write that

although the view of orientation columns as discrete slabs has been abandoned, the hypercolumn is still a valid concept, denoting a unit containing a full set of values for any given receptive field parameter (ibid, p. 841).

This example shows that after conceptual retirement, researchers can study sequence regularity without being committed to discrete anatomical boundaries (C1). Thus, conceptual retirement is consistent with (DR), because scale-dependent columnar properties can occur independently from one another. Yet, conceptual retirement also implies that novel descriptions of functional architecture are not bound to the column concept. Just as the MFH view can be expressed without referring to columns (Fig. 2), researchers could talk about sequence regular orientation maps without mentioning columns at all. This deflationary attitude towards column research may well represent the mainstream amongst neuroscientists today. Many column and barrel researchers, for instance, accept the generalization that "thalamic input to cortical layer 4 organized into $400-500 \mu \mathrm{m}$ clusters" (Markram et al., 2015, p. 461, p. 474). Maintaining this generalization is compatible with the claim that cells in other cortical layers are connected horizontally beyond the boundaries defined by thalamocortical input alone (Narayanan et al., 2015). These examples suggest that researchers still use insights from column research as a guide, while at the same time trying to avoid past mistakes that stem from commitments of the classical columnar outlook. If this attitude is the mainstream view amongst neuroscientists, then this supports the case for conceptual retirement and speaks against eliminating "cortical column". To show how widespread this attitude is in current research, I close by mentioning three epistemic goals to which the retired column concept continues to contribute.

The first goal is to use the column concept to assess the precision of a novel instrument. For example: Yacoub, Harel, and Ugurbil (2008), used high-resolution functional magnetic resonance imaging (fMRI) to map ocular dominance and orientation columns in the human V1. The goal of this study was to use well-known functional features to "test the veracity of the maps obtained in the human brain" (ibid., p. 10609) with high-resolution fMRI. The study showed that this tool can measure "structures with $1 \mathrm{~mm}$ dimensions can be mapped in areas void of large vessels" (ibid., p. 10611), such as ocular dominance or orientation columns. The use of "cortical column" to assess the precision of fMRI is independent of identifying a building block, because fMRI can be used 
Preprint to appear in Studies in History and Philosophy of Science, doi: 10.1016/j.shpsa.2020.09.010. Please quote published version.

to map all kinds of mesoscale circuits, whether or not they are columnar in shape or function. This means that researchers are not bound to use "cortical column" when describing results from highresolution fMRI.

The second goal is that researchers can use columnar structures to study cortical development. Hubel and Wiesel's deprivation experiments with kittens were crucial to discover the effects of sensory experience on the development of cortical structure. The success of eir experiments depended - at least counterfactually — on columnar structure: "had geniculate afferents serving each eye been distributed diffusely within the cortex, this classic experiment would have been impossible" (Horton \& Adams, 2005 p. 856). Columnar structures such as ocular dominance columns are useful to study developmental mechanisms even if their functional significance varies across species. Thus, researchers can use columnar structures to study development without assuming that it refers to a building block in the mammalian neocortex.

The third goal is the use of "cortical column" in computer simulations. Consider the Blue Brain Project, which initially adopted the building block picture (Markram, 2006). This is not the case anymore in a large-scale simulation of neocortical circuitry in the hindlimb somatosensory cortex of the juvenile rat (Markram et al., 2015). This study uses "minicolumn" without committing to $(\mathrm{C} 1)$ because the simulated area contains "no anatomically defined horizontal columnar organization" (ibid., p. 462). So while they learned a cautionary tale from column research, these researchers were also guided by it because they used the generalization that thalamic input to layer 4 is $400-500 \mu \mathrm{m}$ wide. The simulations show that thalamic input leads first to localized activity within a minicolumn, before spreading weakly but uniformly to all neighboring units (cf. ibid., Fig. 14D). These results are intended to provide general insights and predictions about any kind of microcircuit. Thus, other researchers can take these results without being bound to describe them as "columnar". This example shows that computational neuroscientists can use "column" to describe vertical units of simulated brain activity without trying to identify a basic building block of the mammalian neocortex. 
Preprint to appear in Studies in History and Philosophy of Science, doi: 10.1016/j.shpsa.2020.09.010. Please quote published version.

\section{Conclusion}

In this paper, I argued that between 1981 and 2005, the column concept developed a patchwork of multiple technique-involving, scale-dependent and domain-specific uses. The patchwork model reveals challenges to the classical columnar outlook and shows why the building block picture of "cortical column" is faulty. Rather than referring to a basic building block of the mammalian neocortex, the column concept refers to diverse kinds of scale-dependent and domain-specific columnar structures with variable functional significance. I argued that once we accept this diverse-kinds picture however, "reports of the death of the column have proved premature" (Da Costa \& Martin 2010 , p. 3). There is no need to eliminate the superordinate concept "cortical column" because neuroscientists can avoid miscommunication by using "cortical column" in a patch-specific manner, and dissolve the debates about columnar function by switching from the faulty building block picture to the successful diverse-kinds picture of "cortical column". Instead of elimination, I propose that "cortical column" has entered conceptual retirement: whereas past column research is no longer normatively binding to current neuroscientists, they can still use its insights both as a guide and as a cautionary tale when investigating functional architecture. Although they can no longer use the column concept to identify a neocortical building block, neuroscientists can still use it for purposes that are independent from this goal, such as assessing the precision of their instruments, studying cortical development, or simulating neocortical circuitry.

Note that the retirement of the column concept does not means that researchers should stop searching for a neocortical building block altogether. It only means that they should use alternative concepts when trying to achieve this goal. I briefly mention two possibilities. First, researchers can replace "cortical column" with "canonical microcircuit" when describing general features of neocortical circuits (da Costa \& Martin, 2010). Using this concept does not commit researchers to (C1) and (C2) because it does not posit discrete anatomical boundaries and allows for functional diversity (ibid., p. 8). It instead describes the minimal circuitry necessary to maintain a balance between excitation and inhibition in response to a pulse stimulus of thalamic input fibers. Depending on which function they want to explain, researchers can add further explanatory details to this minimal description of cortical circuitry (Haueis, 2018, sec. 3.2). This feature allows them to generalize the canonical microcircuit concept across areas and species to explain different cognitive functions and computational regimes. The second possibility is to extend "central pattern generator" from invertebrate and subcortical systems to cortex (Yuste, MacLean, Smith, \& Lansner, 
Preprint to appear in Studies in History and Philosophy of Science, doi: 10.1016/j.shpsa.2020.09.010. Please quote published version.

2005). While the column concept describes serial responses to sensory stimuli, "central pattern generator" describes recurrently connected pacemaker and follower modules which oscillate in the absence of sensory feedback. This concept has been successfully used to explain how noncortical circuits contribute to subsistence functions like breathing or digestion, but it is currently unclear how researchers could extend "central pattern generator" to the cortex to explain cognitive functions (Haueis, 2018, sec. 4.2). Regardless which of the two concepts researchers use in the future, the conceptual retirement of the column concept allows researchers to incorporate insights and avoid pitfalls from column research when generating novel descriptions of the functional architecture of the cortex.

\section{References}

Albright, T. D., Desimone, R., \& Gross, C. G. (1984). Columnar organization of directionally selective cells in visual area MT of the macaque. Journal of Neurophysiology, 51(1), 16-31. https://doi.org/10.1152/jn.1984.51.1.16

Burnston, D. C. (2016). A contextualist approach to functional localization in the brain. Biology and Philosophy, 31(4), 527-550. https://doi.org/10.1007/s10539-016-9526-2

Burnston, D. \& Haueis, P. (2020). Evolving concepts of "hierarchy" in systems neuroscience. In M. Viola and F. Calzavarini (eds.). New challenges in the philosophy of neuroscience. Berlin: Springer.

Bursten, J. R. (2016). Smaller than a breadbox: scale and natural kinds. The British Journal for the Philosophy of Science. doi: https://doi.org/10.1093/bjps/axw022

Brigandt, I. (2010). The epistemic goal of a concept: accounting for the rationality of semantic change and variation. Synthese, 177, 19-40. https://doi.org/10.1007/s11229-009-9623-8.

Catania, K. C. (2002). Barrels, stripes, and fingerprints in the brain - implications for theories of cortical organization. Journal of Neurocytology, 31(3-5), 347-358. https://doi.org/10.1023/a:1024186329012

Colaço, D. (2018). Rethinking the role of theory in exploratory experimentation. Biology \& Philosophy, 33(5), 38. https://doi.org/10.1007/s10539-018-9648-9

Da Costa, N. M., \& Martin, K. A. C. (2010). Whose Cortical Column Would that Be? Frontiers in Neuroanatomy, 4, 16. https://doi.org/10.3389/fnana.2010.00016

DeAngelis, G. C., \& Newsome, W. T. (1999). Organization of disparity-selective neurons in Macaque area MT. Journal of Neuroscience, 19(4), 1398. https://doi.org/10.1523/JNEUROSCI.19-04-01398.1999

Ebdon, M. (1993). Is the cerebral neocortex a uniform cognitive architecture? Mind \& Language, 8(3), 368-395. https://doi.org/10.1111/j.1468-0017.1993.tb00291.x 
Preprint to appear in Studies in History and Philosophy of Science, doi: 10.1016/j.shpsa.2020.09.010. Please quote published version.

Eccles, J. C. (1981). The modular operation of the cerebral neocortex considered as the material basis of mental events. Neuroscience, 6(10), 1839-1855. https://doi.org/10.1016/03064522(81)90027-0

Fodor, J. A. (1983). The modularity of mind: An essay on faculty psychology. Cambridge (Mass.): The MIT Press.

Haueis, P. (2016). The life of the cortical column: Opening the domain of functional architecture of the cortex (1955-1981). History and Philosophy of the Life Sciences, 38(3), 2. https://doi.org/10.1007/s40656-016-0103-4

Haueis, P. (2018). Beyond cognitive myopia: a patchwork approach to the concept of neural function. Synthese, 195(12), 5373-5402. https://doi.org/10.1007/s11229-018-01991-z

Horton, J. C., \& Adams, D. L. (2005). The cortical column: A structure without a function. Philosophical Transactions of the Royal Society of London B, 360(1456), 837-862. https://doi.org/10.1098/rstb.2005.1623

Hubel, D. H. (1986). Blobs and color vision. Cell Biophysics, 9(1-2), 91-102. https://doi.org/10.1007/BF02797376

Hubel, D. H., \& Livingstone, M. S. (1987). Segregation of form, color, and stereopsis in primate area 18. Journal of Neuroscience, 7(11), 3378-3415. https://doi.org/10.1523/JNEUROSCI.07-11-03378.1987

Hubel, D. H., \& Wiesel, T. N. (1977). Ferrier lecture 1972. Functional architecture of macaque monkey visual cortex. Philosophical Transactions of the Royal Society of London B, 198(1130), 1-59. https://doi.org/10.1098/rspb.1977.0085

Katz, L. C., Gilbert, C. D., \& Wiesel, T. N. (1989). Local circuits and ocular dominance columns in monkey striate cortex. Journal of Neuroscience, 9(4), 1389-1399. https://doi.org/10.1523/JNEUROSCI.09-04-01389.1989

Linden J. F. \& Schreiner, C. E. (2003). Columnar Transformations in Auditory Cortex? A Comparison to Visual and Somatosensory Cortices. Cerebral Cortex 13(1), 83-89.

Livingstone, M., \& Hubel, D. H. (1988). Segregation of form, color, movement, and depth: anatomy, physiology, and perception. Science, 240(4853), 740-749. https://doi.org/10.1126/science.3283936

Livingstone, M. S., \& Hubel, D. H. (1984). Anatomy and physiology of a color system in the primate visual cortex. Journal of Neuroscience, 4(1), 309-356.

Livingstone, M. S., \& Hubel, D. H. (1987). Psychophysical evidence for separate channels for the perception of form, color, movement, and depth. Journal of Neuroscience, 7(11), 34163468. https://doi.org/10.1523/JNEUROSCI.07-11-03416.1987

Love, A. C. (2013). Theory is as theory does: scientific practice and theory structure in biology. Biological Theory, 7(4), 325-337. https://doi.org/10.1007/s13752-012-0046-2

Markram, H., Muller, E., Ramaswamy, S., Reimann, M.W., Abdellah, M., Sanchez, C.A., Ailamaki, A., Alonso-Nanclares, L., Antille, N., Arsever, S., Kahou, G.A., Berger, T.K., Bilgili, 
Preprint to appear in Studies in History and Philosophy of Science, doi: 10.1016/j.shpsa.2020.09.010. Please quote published version.

A. et al. (2015). Reconstruction and simulation of cortical microcircuitry. Cell 163(2), 456-92. https://doi.org/10.1016/j.cell.2015.09.029

Markram, H. (2006). The Blue Brain Project. Nature Reviews Neuroscience, 7(2), 153-160. https://doi.org/10.1038/nrn1848

Mountcastle, V. B. (1957). Modality and topographic properties of single neurons of cat's somatic sensory cortex. Journal of Neurophysiology, 20(4), 408-434. https://doi.org/10.1152/jn.1957.20.4.408

Mountcastle, V. B. (1978). An organizing principle for cerebral function: the unit module and the distributed system. In Edelman, G.M., Mountcastle, V.B. (Ed.), The mindful brain (pp. 7-50). Cambridge, MA: MIT Press.

Mountcastle, V. B. (1997). The columnar organization of the neocortex. Brain, 120(4), 701-722. https://doi.org/10.1093/brain/120.4.701

Mountcastle, V. B., Lynch, J. C., Georgopoulos, A., Sakata, H., \& Acuna, C. (1975). Posterior parietal association cortex of the monkey: Command functions for operations within extrapersonal space. Journal of Neurophysiology, 38(4), 871-908.

https://doi.org/10.1152/jn.1975.38.4.871

Molnár, Z. 2013. "Cortical column.” In Neural Circuit Development and Function in the Healthy and Diseased Brain, edited by John L. R. Rubenstein and Pasko Rakic, 109-29. Amsterdam, Boston: Elsevier/AP.

Narayanan, R. T., Egger, R., Johnson, A. S., Mansvelder, H. D., Sakmann, B., Kock, C. P. J. de, \& Oberlaender, M. (2015). Beyond columnar organization: Cell type- and target layer-specific principles of horizontal axon projection patterns in rat vibrissal cortex. Cerebral Cortex, 25(11), 4450-4468. https://doi.org/10.1093/cercor/bhv053

Novick, A. (2018). The fine structure of 'homology'. Biology and Philosophy, 33(1-2), 556. https://doi.org/10.1007/s10539-018-9617-3

Phillips, D. P., \& Irvine, D. R. (1983). Some features of binaural input to single neurons in physiologically defined area AI of cat cerebral cortex. Journal of Neurophysiology, 49(2), 383395. https://doi.org/10.1152/jn.1983.49.2.383

Purves, D., Riddle, D. R., \& LaMantia, A. S. (1992). Iterated patterns of brain circuitry (or how the cortex gets its spots). Trends in Neurosciences, 15(10), 362-368.

Rakic, P. (2008). Confusing cortical columns. Proceedings of the National Academy of Sciences of the United States of America, 105(34), 12099-12100.

https://doi.org/10.1073/pnas.0807271105

Reser, D. H., Fishman, Y. I., Arezzo, J. C. \& Steinschneider, M. (2000). Binaural interactions in primary auditory cortex of the awake macaque. Cerebral Cortex 10(6) 574-584. https://doi.org/10.1093/cercor/10.6.574

Rockland, K. S., \& Ichinohe, N. (2004). Some thoughts on cortical minicolumns. Experimental Brain Research, 158(3), 265-277. https://doi.org/10.1007/s00221-004-2024-9 
Preprint to appear in Studies in History and Philosophy of Science, doi: 10.1016/j.shpsa.2020.09.010. Please quote published version.

Rockel, A. J., Hiorns, R. W. and Powell, T.P.S. (1980). The basic uniformity in structure of the neocortex. Brain, 103, 221-244 https://doi.org/10.1093/brain/103.2.221

Roe, A. W., \& Ts'o, D. Y. (1995). Visual topography in primate V2: multiple representation across functional stripes. Journal of Neuroscience, 15(5), 3689-3715. https://doi.org/10.1523/JNEUROSCI.15-05-03689.1995

Stettler, D. D., Das, A., Bennett, J., \& Gilbert, C. D. (2002). Lateral connectivity and contextual interactions in macaque primary visual cortex. Neuron, 36(4), 739-750. https://doi.org/10.1016/S0896-6273(02)01029-2

Swindale, N. V. (1990). Is the cerebral cortex modular? Trends in Neurosciences, 13(12), 487492. https://doi.org/10.1016/0166-2236(90)90082-1

Szentágothai, J. (1978). The Ferrier lecture, 1977. The neuron network of the cerebral cortex: A functional interpretation. Proceedings of the Royal Society of London. Series B, Biological Sciences, 201(1144), 219-248. https://doi.org/10.1098/rspb.1978.0043

Tanaka, K. (1996). Inferotemporal cortex and object vision. Annual Review of Neuroscience, 19, 109-139. https://doi.org/10.1146/annurev.ne.19.030196.000545

Tanigawa H., Rockland K.S., \& Tanifuji, M. (2004). Relationship between horizontal connections and functional structure revealed by intrinsic signal imaging, unit recording, and anatomical tracing in macaque anterior inferotemporal cortex (area TE). Society for Neuroscience Abstracts 30, 300-311.

Taylor, H., \& Vickers, P. (2017). Conceptual fragmentation and the rise of eliminativism. European Journal for Philosophy of Science 7(1): 17-40. https://doi.org/10.1007/s13194-016-01362.

Wiesel, T. N., \& Gilbert, C. D. (1983). The Sharpey-Schafer lecture. Morphological basis of visual cortical function. Quarterly Journal of Experimental Physiology, 68(4), 525-543.

Wilson, M. (2006). Wandering significance. An essay in conceptual behavior. Oxford: Clarendon Press.

Wilson, M. (2017). Physics Avoidance. Oxford: Clarendon Press.

Woolsey, T. A., \& van der Loos, H. (1970). The structural organization of layer IV in the somatosensory region (SI) of mouse cerebral cortex. The description of a cortical field composed of discrete cytoarchitectonic units. Brain Research, 17(2), 205-242. https://doi.org/10.1016/0006-8993(70)90079-x

Yacoub, E., Harel, N., \& Ugurbil, K. (2008). High-field fMRI unveils orientation columns in humans. Proceedings of the National Academy of Sciences of the United States of America, 105(30), 10607-10612. https://doi.org/10.1073/pnas.0804110105

Yuste, R., MacLean, J. N., Smith, J., \& Lansner, A. (2005). The cortex as a central pattern generator. Nature Reviews. Neuroscience, 6(6), 477-483. https://doi.org/10.1038/nrn1686 